\title{
Diversity of uropathogens and their resistogram in diabetic and non-diabetic patients in sub Himalayan region of Uttarakhand, India: A case control study
}

Background: Both symptomatic and asymptomatic urinary tract infections (UTIs) are thought to occur more frequently in diabetic patients. Local data about the antimicrobial resistance of Uropathogens should be available for proper therapeutic interventions of UTI. Objective: To evaluate the spectrum of the Uropathogens and their profiles of antimicrobial resistance on a series of diabetic and non-diabetic patients. Materials and Methods: A Case-Control study with 100 participants was conducted targeting the Diabetic and Non-diabetic population, symptomatic or asymptomatic for UTI. Antibiotic sensitivity test was done on each of the isolates and the results of the antibiogram were compared with that of control group (nondiabetic group). The statistical analysis was done by Chi-Square Test, Fisher exact test using statistical product and service solutions formerly known as Statistical Package for the Social Sciences (SPSS) 16.0 Version. Results: Most common isolate responsible for UTI was Escherichia coli followed by Klebsiella, Enterobacter, Proteus, Citrobacter, Acinetobacter and Candida. 93.3\% and $86.6 \%$ of the isolates were sensitive to Amikacin and Amoxycillin-clavulanic acid respectively for Non Diabetics. Whereas isolates from diabetic group were 77.7 and $50 \%$ sensitive to Amikacin and Amoxycillin-clavulanic acid respectively. Highest resistance was seen for Cefuroxime for the isolates from both diabetic and non-diabetic group with 53.3 and $72.2 \%$ respectively. Significant difference in resistance pattern was observed in Amoxycillin-clavulanic acid, cefazolin, piperacillin- tazobactam and ticarcillin-clavulanic acid. Conclusion: Culture of urine and susceptibility testing of isolated organisms is strongly advocated in the clinical management of impending complication in diabetic individuals.

Key words: Diabetes, resistance pattern, symptomatic and asymptomatic, urinary pathogens

Address for correspondence: Dr. Shekhar Pal,

Department of Microbiology and Immunology, Veer Chandra Singh

Garhwali Government Medical

Sciences and Research Institute, Srinagar Garhwal,

Uttarakhand - 246 174, India.

E-mail: shekharpal@gmail.com

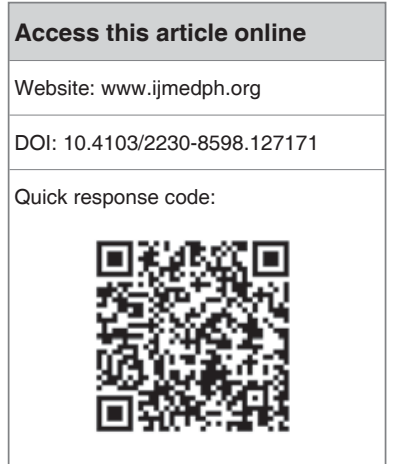

\section{INTRODUCTION}

Urinary tract infections are the most commonly found bacterial infections, accounting for nearly seven million hospital visits and one million emergency department visits, resulting in 100,000 hospitalizations of women, the elderly and patients with spinal cord injuries, catheters, multiple sclerosis, HIV and also diabetes. ${ }^{[1]}$

Several severe and less commonly encountered urinary tract infections (UTIs) are thought to occur more frequently in diabetic patients. ${ }^{[2]}$ In a recent study from Europe, asymptomatic bacteriuria was more prevalent among women with diabetes $(26 \%)$ than in women without diabetes $(6 \%) \cdot{ }^{[3]}$ Diabetic patients are at a high risk of development of UTIs, so it is recommended that special attention is paid to them, especially for the management of bacterial UTIs. ${ }^{[4]}$ Various risk factors such as sexual intercourse, age, duration of diabetes, poor glycemic control, and complications of diabetes are associated with UTI. ${ }^{[5]}$

A high incidence of urinary tract infections has been observed among patients with comorbid illness such as diabetes than non-diabetic, ${ }^{[6]}$ probably due to alteration in genitourinary system, debilitated 
immune system, altered bacterial adhesion to the uroepithelium, due to abnormality of Tammhorsfal protein, granulocyte dysfunction, the presence of diabetic cystopathy and microvascular disease in kidneys. ${ }^{[7]}$ Moreover, among the diabetic patients, females (42.8\%) are prone to UTI than males $(34.1 \%)^{[8]}$ along with high prevalence of asymptomatic bacteriuria..$^{[9]}$ Treatment of UTI cases is often started empirically and a large proportion of unrestrained antibiotic usage results in upsurge of resistance among the uropathogens in both community and health care settings. ${ }^{[10]}$ The local data about the antimicrobial resistance of Uropathogens should be available for proper therapeutic interventions of UTI. For this purpose the study had been designed to evaluate the spectrum of the uropathogens and their profiles of antimicrobial resistance on a series of diabetic and non-diabetic patients.

\section{MATERIALS AND METHODS}

A Case-Control study with 100 participants was conducted from august 2012 to January 2013 in Department of Microbiology and Immunology at Veer Chandra Singh Garhwali Government Medical Science And Research Institute and attached HNB Base Hospital, Srinagar, Pauri-Garhwal, Uttarakhand, targeting the Diabetic and Non-diabetic population, symptomatic or asymptomatic for UTI.

Patients attending/admitted to HNB base hospital with fasting blood glucose level above (Diabetic) and below $110 \mathrm{mg} / \mathrm{dl}$ (Non-diabetic) and no prior history of UTI for past three months and without any medication for past one month were included in the study. Patients with on-going medication for urinary tract infection and Patients with any intubation or catheterization were excluded from the study. Clean catch mid stream urine sample were collected in a pre- sterilized universal container after educating the patient. Specimens were transported within 30min of collection to the laboratory for processing. Routine wet-mount, of the properly mixed un-centrifuged urine sample, was performed along with Gram Staining. Aerobic Culture was done on 5\% Sheep blood agar and MacConkey agar. Kass Concept of Semi Quantitation was employed for the determination of bacterial load. Un-centrifuged specimen was inoculated on Blood Agar and MacConkey Agar. Antibiotic sensitivity test was done according to CLSI guidelines, on Mueller Hinton agar by Kirby-Bauer method. Concept of significant bacteriuria was followed while considering the patient's information (age, sex) and any past history. The statistical analysis was done by Chi-Square Test, Fisher exact test using Statistical Package for the Social Sciences (SPSS) 16.0 Version.

\section{RESULT}

Fifty each urine samples of both diabetic and non-diabetic patients were screened for symptomatic and asymptomatic bacteriuria. Out of 50 diabetic patients 26 were males and 24 were females.[Table 1] In this study, all the patients were above 30 years of age. In diabetic group $6(12 \%)$ patients were between 31 and 40 years of age and remaining were above 41 years, whereas 7 (14\%) were between 31 and 40 years of age and remaining were above 41 years among nondiabetic group [Table 2]. Rate of asymptomatic bacteriuria among diabetic and non-diabetic males was $58.8 \%$ and $41.2 \%$ respectively followed by $57.1 \%$ diabetic and $42.9 \%$ non-diabetic females respectively [Table 3].

Escherichia coli was the most common isolate responsible for asymptomatic UTI in $45 \%$ of diabetic and $63 \%$ of non-diabetic patients followed by Klebsiella spp. of which isolation rate was $14 \%$ in diabetic and 13\% in non-diabetic. Enterobacter and Proteus spp. constituted $9 \%$ of infection among diabetic and 6\% in non-diabetic. Citrobacter was isolated only in non-diabetic group. Acinetobacter (4.5\%) was isolated only in diabetic group. Candida species constitute the major part of infectious etiology ranging between $4(18.2 \%)$ among diabetic and 1 $(6.3 \%)$ in non-diabetic study population. Out of total Candida species Candida albicans was isolated in $3(75 \%)$ and 1 (25\%) in diabetic and non-diabetics respectively, whereas Non albicans Candida was isolated only in $1(4.5 \%)$ of total diabetic isolates [Table 5]. Among the first line drug used for treating UTI, Amikacin and Amoxycillin-clavulanic acid was found to be most sensitive for the uropathogens isolated in our study. $93.3 \%$ and $86.6 \%$ of the isolates were sensitive to Amikacin and Amoxycillin-clavulanic acid respectively for Non Diabetics. Whereas isolates from diabetic group were 77.7 and 50\% sensitive to Amikacin and Amoxycillin-clavulanic acid respectively. Highest resistance was seen

\begin{tabular}{|c|c|c|c|}
\hline Gender & Diabetics & Non-diabetics & Total \\
\hline Male & 26 & 23 & 49 \\
\hline Female & 24 & 27 & 51 \\
\hline Total & 50 & 50 & 100 \\
\hline
\end{tabular}

\begin{tabular}{lccc}
$\begin{array}{l}\text { Table 2: Age wise distribution of bacterial isolates } \\
\text { in diabetics and controls } \\
\text { Age }\end{array}$ & $\begin{array}{c}\text { Diabetics (Number } \\
\text { of Isolates) }\end{array}$ & $\begin{array}{c}\text { Non-Diabetics } \\
\text { (Number of Isolates) }\end{array}$ & Total \\
\hline $0-10$ & 0 & 0 & 0 \\
$11-20$ & 0 & 0 & 0 \\
$21-30$ & 0 & 0 & 0 \\
$31-40$ & 4 & 3 & 7 \\
41 and Above & 18 & 13 & 31 \\
Total & 22 & 16 & 38 \\
\hline
\end{tabular}

Table 3: Gender wise distribution of significant bacterial isolates in diabetic and controls

\begin{tabular}{lccccc}
\hline \multirow{2}{*}{ Isolate } & \multicolumn{2}{c}{ Diabetic } & & \multicolumn{2}{c}{ Non-Diabetic } \\
\cline { 2 - 3 } \cline { 5 - 6 } & Male & Female & & Male & Female \\
\hline Escherichia coli & 5 & 5 & & 4 & 6 \\
Klebsiella species & 1 & 2 & & 1 & 1 \\
Proteus species & 0 & 2 & & 0 & 1 \\
Candida albicans & 0 & 3 & & 0 & 1 \\
Non-albicans Candida & 1 & 0 & & 0 & 0 \\
Enterobacter species & 2 & 0 & & 1 & 0 \\
Citrobacter species & 0 & 0 & & 1 & 0 \\
Acinetobacter species & 1 & 0 & & 0 & 0 \\
Total & 10 & 12 & & 7 & 9 \\
\hline
\end{tabular}


for Cefuroxime for the isolates from both diabetic and non diabetic group with 53.3 and $72.2 \%$ respectively. Though the resistance pattern of most of the isolates from both the study group were not significant $(P>0.05)$, except for Amoxycillin-clavulanic acid, cefazolin, piperacillintazobactam and ticarcillin-clavulanic acid which displayed significant difference between resistogram of the two study groups [Table 6].

\section{DISCUSSION}

Over the years, evidences from many epidemiological studies have suggested that asymptomatic bacteriuria and UTI is a common occurrence in women with diabetes than in those without diabetes. ${ }^{[1]}$ Long term cohort studies have also reported no negative outcomes attributable to asymptomatic bacteriuria, although women with asymptomatic bacteriuria do have an increased frequency of symptomatic infection. ${ }^{[12,13]}$ Although uropathologic complications are common in men and women with diabetes, data to define expected prevalence, incidence and risk factors as well as interventions to reduce the risk of developing complications are limited. Furthermore, the majority of data has been collected in patients with type 2 diabetes and in females; therefore data regarding these relationships in type one diabetes and in men are less available. Recent study has focused in the association of Asymptomatic bacteriuria ASB to diabetes. ${ }^{[12,14,15]}$ Both symptomatic and asymptomatic urinary tract infection are reported to occur with increased frequency in women with diabetes. ${ }^{[16,17]}$ In women without diabetes, ASB is relatively uncommon and increases risk of UTI but does not lead to serious sequelae ${ }^{[18]}$ Diabetic women have a two to three fold higher prevalence of ASB and are at risk of developing more serious consequences. ${ }^{[14,15]}$ Women with type two diabetes and ASB, have an increased risk for development of a symptomatic UTI ${ }^{[19]}$ and women with type one diabetes are at increased risk for pyelonephritis and subsequent impairment of renal function. Uropathogens were isolated more in diabetics than in nondiabetic [Table 4].

The prospective cohort of present study illustrates the prevalence of ASB more among diabetic females (57.1\%) than non-diabetic females $(42.9 \%$ ) followed by $58.8 \%$ diabetic and $41.2 \%$ non-diabetic males respectively [Table 3]. This corroborate the reports of Raz and Stomm (1992) ${ }^{[29]}$ that females are more commonly affected with UTI than males ${ }^{[25]}$ and with that of Geerlings, Stolk and Camp (2001) ${ }^{[12]}$ that women with Diabetes mellitus DM are about 2-3 times more likely to have bacteria in their bladder than women without DM. ${ }^{[12,28]}$

E. coli was the most commonly isolated Uropathogens in the urine of $\mathrm{DM}$ and non DM patients in our study. However, we found that there was a trend towards a lower proportion of UTI caused by the E. coli in DM compared with non- DM patients (45 versus 63 respectively) [Table 5]. Other investigators have reported similar findings. ${ }^{[20,39]}$

Next to E. coli we isolated Klebsiella spp. of which isolation rate was $14 \%$ in diabetics and $13 \%$ in nondiabetics. This corroborates the findings of other researchers who isolated klebsiella and Proteus in 12.7 and $6.3 \%$ respectively. ${ }^{[21]}$ Geerlings et al., ${ }^{[22]}$ isolated Klebsiella in $14.3 \%$, Janifer et al., isolated Klebsiella in $13.5 \%$. $^{[23]}$
Subsequent isolated organisms were Proteus spp. and Enterobacter which constituted $9 \%$ of the infection among diabetic and $6 \%$ in nondiabetic. This finding is in total disagreement to the findings of B pargavi et al., which isolated Proteus in $85 \%$ of diabetic patients. ${ }^{[24]}$

DM is a common predisposing factor for UTI caused by fungi, particularly Candida spp. ${ }^{[20,22]}$ This is because diabetes affects much system that protect against general infections and against UTI specifically. ${ }^{[2]}$ Poor circulation in diabetes reduces the ability of macrophages and polymorph nuclear (PMN) cells to get away where they are required and even when they do, they are less able to phagocytize the offending bacteria and kill them than normal PMNs. It may also be due to bladder dysfunction caused by diabetic neuropathy which allows urine to remain in static pools for long period of time, providing luxurious ponds for bacteria to thrive in. ${ }^{[27]}$

Changes in host defence mechanism, the presence of diabetic cystopathy and of microvascular disease in the kidneys may play a role in the higher incidence of UTI in diabetic patients. ${ }^{[32]}$

Age appeared to play major role in prevalence of bacterial pathogens among DM as those between 30 and 41 years and above age had more isolates [Table 2]. This can be derived from the fact that people in this age group are more prone to diabetes and therefore their urine provides conducive condition for bacteria to thrive. ${ }^{[26]}$ Although urologic complications are common and major health problems in men and women with diabetes, data to define expected prevalence, incidence and risk factors as well as

\begin{tabular}{|c|c|c|c|c|}
\hline & \multicolumn{2}{|c|}{ Diabetic } & \multicolumn{2}{|c|}{ Non-Diabetic } \\
\hline & $\begin{array}{l}\text { No. of } \\
\text { Isolates }\end{array}$ & Percentage & $\begin{array}{l}\text { No. of } \\
\text { Isolates }\end{array}$ & Percentage \\
\hline With bacteriuria & 22 & 44 & 16 & 32 \\
\hline Without bacteriuria & 28 & 66 & 34 & 68 \\
\hline Total & 50 & 100 & 50 & 100 \\
\hline
\end{tabular}

\begin{tabular}{|c|c|c|c|c|}
\hline \multirow[t]{2}{*}{ Isolate } & \multicolumn{2}{|c|}{ Diabetic } & \multicolumn{2}{|c|}{ Non-Diabetic } \\
\hline & $\begin{array}{c}\text { No. of } \\
\text { Isolates }\end{array}$ & Percentage & $\begin{array}{c}\text { No. of } \\
\text { Isolates }\end{array}$ & Percentage \\
\hline Escherichia coli & 10 & 45 & 10 & 63 \\
\hline Klebsiella species & 3 & 14 & 2 & 13 \\
\hline Proteus species & 2 & 09 & 1 & 6 \\
\hline Candida albicans & 3 & 14 & 1 & 6 \\
\hline $\begin{array}{l}\text { Non-albicans } \\
\text { Candida }\end{array}$ & 1 & 4.5 & 0 & 0 \\
\hline $\begin{array}{l}\text { Enterobacter } \\
\text { species }\end{array}$ & 2 & 9 & 1 & 6 \\
\hline $\begin{array}{l}\text { Citrobacter } \\
\text { species }\end{array}$ & 0 & 0 & 1 & 6 \\
\hline $\begin{array}{l}\text { Acinetobacter } \\
\text { species }\end{array}$ & 1 & 4.5 & 0 & 0 \\
\hline Total & 22 & 100 & 16 & 100 \\
\hline
\end{tabular}




\begin{tabular}{|c|c|c|c|c|c|}
\hline \multirow[t]{2}{*}{ Drugs } & \multicolumn{2}{|c|}{ Non-Diabetic } & \multicolumn{2}{|c|}{ Diabetic } & \multirow[t]{2}{*}{$P$ value } \\
\hline & Sensitive (\%) & Resistance (\%) & Sensitive (\%) & Resistance (\%) & \\
\hline Amikacin & $28(93.33)$ & $2(6.67)$ & $28(77.78)$ & $8(22.22)$ & $x^{2}=1.989 ; P=0.1585$ \\
\hline Ampicillin & $16(53.33)$ & $14(46.67)$ & $12(33.33)$ & $24(66.67)$ & $x^{2}=1.923 ; P=0.1655$ \\
\hline Amoxycillin-clavulanic acid & $26(86.67)$ & $4(13.33)$ & $18(50)$ & $18(50)$ & $x^{2}=8.319 ; P=0.0039$ \\
\hline Cefazolin & $18(60)$ & $12(40)$ & $10(27.78)$ & $26(72.22)$ & $x^{2}=5.699 ; P=0.0170$ \\
\hline Cefuroxime & $14(46.67)$ & $16(53.33)$ & $14(38.89)$ & $22(61.11)$ & $X^{2}=0.149 ; P=0.699$ \\
\hline Cefotaxime & $18(60)$ & $12(40)$ & $20(55.56)$ & $16(44.44)$ & $x^{2}=0.013 ; P=0.909$ \\
\hline CiProfloxacin & $18(60)$ & $18(40)$ & $20(55.56)$ & $16(44.44)$ & $x^{2}=0.056 ; P=0.8134$ \\
\hline Cotrimoxazole & $18(60)$ & $12(40)$ & $16(44.44)$ & $20(55.56)$ & $x^{2}=1.024 ; P=0.3117$ \\
\hline Aztreonam & $16(53.33)$ & $14(46.67)$ & $14(66.11)$ & $22(38.89)$ & $x^{2}=0.856 ; P=0.355$ \\
\hline Gentamicin & $18(60)$ & $12(40)$ & $14(38.89)$ & $22(66.11)$ & $x^{2}=1.412 ; P=0.2347$ \\
\hline Nitrofurantoin & $28(93.33)$ & $2(6.67)$ & $26(72.22)$ & $10(27.78)$ & $x^{2}=3.586 ; P=0.058$ \\
\hline CefoPerazone-sulbactam & $28(93.33)$ & $2(6.67)$ & $26(72.22)$ & $10(27.78)$ & $X^{2}=3.586 ; P=0.058$ \\
\hline Piperacillin-tazobactam & $28(93.33)$ & $2(6.67)$ & $24(66.67)$ & $12(33.33)$ & $X^{2}=5.458 ; P=0.019$ \\
\hline Ticarcillin-clavulanate & $28(93.33)$ & $2(6.67)$ & $24(66.67)$ & $12(33.33)$ & $X^{2}=5.458 ; P=0.019$ \\
\hline Meropenem & $28(93.33)$ & $2(6.67)$ & $26(72.22)$ & $10(27.78)$ & $x^{2}=3.586 ; P=0.058$ \\
\hline
\end{tabular}

interventions to reduce the risk of developing these complications are limited. Intensive glycemic control delays the onset and progression of micro vascular complications of diabetes in both type one and type two diabetes. ${ }^{[30,31]}$

Increasing antimicrobial resistance among bacteria is a major concern. The most important variable promoting resistance is the indiscriminate use of antimicrobial agents. Rational use of these agents requires the identification of clinical situations in which antimicrobial therapy is not indicated.

Regarding antimicrobial resistance profile, we observed no significant difference $(P>0.05)$ between the two groups for ampicillin, cotrimoxazole, ciprofloxacin and nitrofurantoin [Table 6]. Although the resistance pattern of the antibiotics summarized in [Table 6], exhibited significant difference for Amoxycillinclavulanic acid $(P=0.0039)$, cefazolin $(P=0.0170)$, Piperacillin$\operatorname{tazobactam}(P=0.019)$ and ticarcillin-clavulanic acid $(P=0.019)$ in diabetic and nondiabetic group. This requires special attention as most authors prefer antimicrobial agents which achieve high levels not only in the urine but also in the urinary tract tissue eg. Fluoroquinolones, Trimethoprim-sulfamethoxazole TMPSMX, Amoxicillin-clavulanic acid. ${ }^{[35,36]}$ Although some authors state that choice of antimicrobial remains the same as that of nondiabetic otherwise healthy subjects. ${ }^{[25,33,34,37,38]}$ The eradication of microorganisms that cause UTI has been reported to be more difficult in diabetic patients than in nondiabetic patients because of an increased frequency of multidrug resistance. ${ }^{[40,41]}$ The outcomes of the results become more prominent in the clinical management of impending complication in diabetic individuals. Our findings strongly advocate culture of urine and susceptibility testing of isolated organisms in order to formulate antibiotic policy of the concerned clinical setup.

These data indicate that routine mechanisms must be established in communities to assess antimicrobial susceptibility of uropathogens and that standard regimen for empirical therapy must be reassessed periodically in light of changing susceptibility patterns. Additional types of studies would enhance our understanding of optimal management of uncomplicated UTIs. Antimicrobial resistance patterns will continue to change, implying that properly designed studies performed in a timely fashion will be necessary to maintain the affectivity of the existing antibiotics. These trials should include not only newly introduced agents but also extant antimicrobials, to gauge their relative importance.

The paucity of knowledge has been a barrier to develop the best strategy to combat the further complications of ASB and to decide the best therapeutic management with special emphasis on type of antimicrobial agent and optimal treatment duration. However, new research initiatives with bigger sample size are solicited to validate the outcome of the study.

\section{ACKNOWLEDGEMENTS}

The authors thankfully acknowledge the support of ICMR-Studentship programme \& Dr. Amit Mittal for carrying out statistical analysis of the article.

\section{REFERENCE}

1. Foxman B. Epidemiology of urinary tract infections: Incidence, morbidity and economic costs. Dis Mon 2003;49:53-70.

2. Ankel F, Wolfson AB, Stapczynski JS. Emphysematous cystitis: A complication of urinary tract infection occurring predominantly in diabetic women. Ann Emerg Med 1990;19:404-6.

3. Geerlings SE, Stolk RP, Camps MJ, Netten PM, Hoekstra JB, Bouter KP, et al. Asymptomatic bacteriuria may be considered a complication in women with diabetes. Diabetes Mellitus Women Asymptomatic Bacteriuria Utrecht-Study Group. Diabetes Care 2000;23:744-9.

4. Meiland R, Geerlings GE, Hoepelman Al. Management of bacterial urinary tract infections in adult patients with diabetes mellitus. Drugs 2002;62:1859-68.

5. Guy Neild H. Urinary tract infection. Medicine. The Medicine publishing company Ltd,Abingdon,UK; 2003. p. 85-90. 
6. Bonadio M, Costarelli S, Morelli G, Tartaglia T. The influence of diabetes mellitus on the spectrum of uropathogens and the antimicrobial resistance in elderly adult patients with urinary tract infection. BMC Infect Dis 2006;6:54:

7. Valerius NH, Eff C, Hansen NE, Karle H, Nerup J, Søeberg B, et al. Neutrophil and lymphocyte function in patients with diabetes mellitus: Acta Med Scand 1982;211:463-7.

8. Dalal S, Nicolle L, Marrs CF, Zhang L, Harding G, Foxman B. Long-Term Escherichia coli symptomatic Bacteriuria among Women with Diabetes Mellitus. Clin Infect Dis 2009;49:491-7.

9. Renko M, Tapanainen P, Pokka T, Uhari M. Meta-Analysis of the Significance of Asymptomatic Bacteriuria in Diabetes. Diabetes Care 2011;34:230-5.

10. Beyene G, Tsegaye W. Bacterial uropathogens in urinary tract infection and antibiotic susceptibility pattern in Jimma University specialized hospital, Southwest Ethiopia. Ethiop J Health Sci 2011;21:141-6.

11. Stapleton A. Urinary tract infections in patients with diabetes. Am J Med 2002;113(Suppl. 1A):80S-4S.

12. Geerlings SE, Stolk RP, Camps MJ, Netten PM, Collet JT, Schneeberger PM, et al. Consequences of asymptomatic bacteriuria in women with diabetes mellitus. Arch Intern Med 2001;161:1421-7.

13. Semetkowska-Jurkiewicz E, Horoszek-Maziaz S, Galinski J, Maritius A, Krupa-Wojciechowska B. The clinical course of untreated asymptomatic bacteriuria in diabetic patients -14 year follow-up. Mater Med Pol 1995;27:91-5.

14. Zhanel GG, Nicolle LE, Harding GK. Prevalence of asymptomatic bacteriuria and associated host factors in women with diabetes mellitus: The Manitoba Diabetic Urinary Infection Study Group. Clin Infect Dis1995;21:316-22.

15. Geerlings SE, Stolk RP, Camps MJ, Netten PM, Hoekstra JB, Bouter PK, et al. Asymptomatic bacteriuria can be considered a diabetic complication in women with diabetes mellitus. Adv Exp Med Biol 2000;485:309-14.

16. Zhanel GG, Harding GK, Nicolle LE. Asymptomatic bacteriuria in patients with diabetes mellitus. Rev Infect Dis 1991;13:150-4.

17. Boyko EJ, Fihn SD, Scholes D, Chen CL, Normand EH, Yarbro P. Diabetes and the risk of acute urinary tract infection among postmenopausal women. Diabetes Care 2002;25:1778-3.

18. Hooton TM, Scholes D, Stapleton AE, Roberts PL, Winter C, Gupta K, et al. A prospective study of asymptomatic bacteriuria in sexually active young women. N Engl J Med 2000;343:992-7.

19. Geerlings SE, Stolk RP, Camps MJ, Netten PM, Collet TJ, Hoepelman Al. Risk factors for symptomatic urinary tract infection in women with diabetes. Diabetes Care 2000;23:1737-41.

20. Ghenghesh KS, Elkateb E, Berbash N, Abdel Nada R, Ahmed SF, Rahouma $A$, et al. Uropathogens from diabetic patients in Libya: Virulence factors and phylogenetic groups of Escherichia coli isolates. $\mathrm{J}$ Med Microbiol 2009;58:1006-14.

21. Ophori EA, Imade P, Johnny EJ. Asymptomatic bacteriuria in patients with type-2 diabetes mellitus. J Bacteriol Res 2001;2:14-7.

22. Joshi N, Caputo GM, Weitekamp MR, Karchmer AW. Infections in patients with diabetes mellitus. N Engl J Med 1999;341:1906-12.

23. Pargavi B, Mekala T, Thamarai Selvi A, Moorthy K. Prevalence of urinary Tract Infection among Diabetes patients in Vandavasi, Tamil nadu, India. Int J Biol Technol 2011;2:42-5.

24. Chukwuocha UM, Emerole CO, Njokuobi TN, Nwawume IC. Urinary tract infections associated with Diabetic patients in the federal medical centre owerri, Nigeria. Global Adv Res J Microbiol 2012;1:62-6.

25. Geerlings SE. Urinary tract infections in patients with diabetes mellitus Epidemiology, Pathogenesis and Treatment. Int $\mathrm{J}$ Antimicrob Agent 2008;31:54-7.

26. Goswami R, Bal CS, Zateri RB, Punjabi GV. Prevalence of urinary tract infection and renal scars in patients with diabetes mellitus. Infect Dis Clin North Am 2001;18:52-41.

27. Achary VN, Jadan SK. Urinary tract infection: Current issues. J Postgrad Med 1980;26:95-8.

28. Horcajada SK, Patel KC, Jain US, Johnson JR. Laboratory diagnosis of urinary tract infections in adult patients. Clin Infect Dis 1999;39:873-7.

29. Raz DS, Stamm WE. Case Study: Infections in diabetes mellitus. Diabetes Spectr 1992;15:37-40.

30. UK Prospective Diabetes Study (UKPDS) Group: Intensive blood-glucose control with sulphonylureas or insulin compared with conventional treatment and risk of complications in patients with type 2 diabetes (UKPDS 33). Lancet 1998;352:837-53.

31. Wan P, Lau J, Chalmore T. Meta-analysis of effects of intensive blood glucose control on the late diabetic complications of type 1 diabetes. Lancet 1993;341:877-90.

32. Sridhar CB, Anjana S, Mathew JT. Acute Infections. RSSDI text book of diabetes mellitus. In: Ahuja MM, Tripathy BB, Sam Moses GP, Chandalia HB, Das AK, Rao PV, editors. Ch. 34, Hyderabaad, India: 2002. p.471-8.

33. Meiland R, Geerlings SE, De Neeling AJ, Hoepelman Al. Diabetes mellitus in itself is not a risk factor for antibiotic resistance in Escherichia coli isolated from patients with bacteriuria. Diabet Med 2004;21:1032-4.

34. Steinke DT, Seaton RA, Phillips G, MacDonald TM, Davey PG. Factors associated with trimethoprim-resistant bacteria isolated from urine samples. J Antimicrob Chemother 1999;43:841-3.

35. Stamm WE, Hooton TM. Management of urinary tract infection in adults N Engl J Med 1993;329:1328-34.

36. Schaeffer AJ. Bacterial urinary tract infections in diabetes. J Urol 1998;160:293.

37. Nicolle LE. A practical guide to antimicrobial management of complicated Urinary tract infection. Drugs Aging 2001;18:243-54.

38. Ronald A, Ludwig E. Urinary tract infection in adults with diabetes. Int $\mathrm{J}$ Antimicrob Agents 2001;17:287-92.

39. Hansen DS, Gottschau A, Kolmos HJ. Epidemiology of Klebsiella bacteraemia: A case control study using Escherichia coli bacteraemia as control. J Hosp Infect 1998;38:119-32.

40. Wright SW, Wrenn KD, Haynes M, Haas DW. Prevalence and risk factors for multidrug resistant uropathogens in ED patients. Am J Emerg Med 2000;24:143-6.

41. Bonadio M, Meini M, Gigli C, Longo B, Vigna A. Urinary tract infection in diabetic patients. Urol Int 1999;63:215-9.

How to cite this article: Prakash R, Pal S, Sharma N, Adekhandi S, Juyal D, Gaurav V. Diversity of uropathogens and their resistogram in diabetic and non-diabetic patients in sub Himalayan region of Uttarakhand, India: A case control study. Int J Med Public Health 2014;4:115-9.

Source of Support: Nil, Conflict of Interest: None declared 